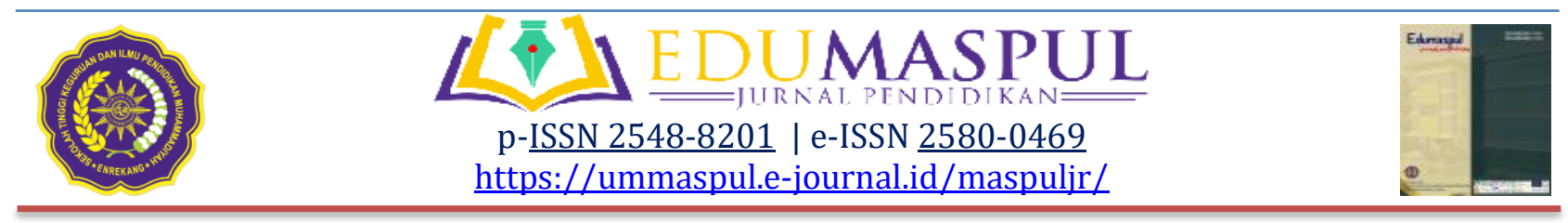

\title{
Pola Pembentukan Solidaritas Sosial dalam Kelompok Sosial Antara Pelajar
}

\author{
Saidang1, Suparman² \\ 1,2Non Formal Education Department, STKIP Muhammadiyah Enrekang, Indonesia. \\ $\triangle$ Corresponding email: 1saidsaidang@gmail.com, 22suparmanpps25@gmail.com
}

\begin{abstract}
Receive: 21-09-2019
Accepted: 30-09-2019

Published: 09-10-2019

Abstrak: Masalah utama dalam penelitian ini yaitu bagaimanakah pola pembentukan solidaritas sosial dalam kelompok sosial dan dampak pola pembentukan solidaritas sosial dalam kelompok sosial antara pelajar di kecamatan Baraka Kabupaten Enrekang. Penelitian ini bertujuan untuk mengetahui pola pembentukan solidaritas sosial dan dampak pola pembentukan solidaritas sosial dalam kelompok sosial antara pelajar di Baraka. Penelitian ini adalah jenis penelitian kualitatif, meliputi rangkaian kegiatan yang sistematik untuk mendapatkan jawaban atas permasalahan yang diajukan. Jika dilihat dari jenis dan obyek yang diteliti, maka penelitian ini dikategorikan sebagai penelitian studi kasus dengan maksud memberikan gambaran tentang pola pembentukan solidaritas sosial dalam kelompok sosial antara pelajar di Baraka. Hasil penelitian menggambarkan bahwa pola pembentukan solidaritas sosial dalam kelompok sosial antara pelajar adalah suatu cara untuk membentuk karakter dan kerukunan anatara pelajar sehingga keharmonisan dan kerja sama akan terjalin baik antar kelas maupun antar sekolah. Dan pada akhirnya akan melahirkan generasi-generasi yang berkarakter yang dapat membawa perubahan yang lebih baik untuk bangsa dan negara dan dampak pola pembentukan solidaritas sosial dalam kelompok sosial antara pelajar di Baraka adalah terjadinya hubungan kerja sama, terjadinya keharmonisan, terhindarnya dari berbagai jenis konflik terciptanya keamanan, ketentraman dan tentunya hal yang paling penting adalah terbentuknya karakter pelajar yang mencerminkan sosok pelajar yang akan menjadi generasi emas di masa yang akan datang. Disamping itu pemerintah dengan mudah merekrut karyawan yang akan di posisikan sesuai dengan keahlian masingmasing.
\end{abstract}

Kata Kunci : Solidaritas sosial, Kelompok sosial, Pendidikan Karakter.

Abstract: The main problem in this research is how the pattern of formation of social solidarity in social groups and the impact of patterns of formation of social solidarity in social groups between students in the district of Baraka, Enrekang Regency. This study aims to determine patterns of formation of social solidarity and the impact of patterns of formation of social solidarity in social groups between students in Baraka. This research is a type of qualitative research, including a series of systematic activities to get answers to the problems raised. When viewed from the types and objects studied, this research is categorized as a case study research with the intention of giving a picture of the pattern of social solidarity formation in social groups between students in Baraka. The results of the study illustrate that the pattern of forming social solidarity in social groups between students is a way to form character and harmony between students so that harmony and cooperation will be established both between classes and between schools. And in the end will give birth to generations of characters who can bring better change for the nation and state and the impact of the pattern of formation of social solidarity in social groups between students in Baraka is the occurrence of cooperative relations, the occurrence of harmony, avoidance of various types of conflicts the creation of security, peace and of course the most important thing is the formation of student character that reflects the figure of students who will become the golden generation in the future. Besides that the government easily recruits employees to be positioned according to their respective expertise.

Keywords: Social solildarity, Social group, Students character. 


\section{PENDAHULUAN}

Apa yang membentuk dasar dari solidaritas bervariasi antara masyarakat. Dalam masyarakat sederhana mungkin terutama berbasis di sekitar nilai-nilai kekerabatan dan berbagi. Dalam masyarakat yang lebih kompleks terdapat berbagai teori mengenai apa yang memberikan kontribusi rasa solidaritas sosial.

Pentingnya mengembalikan nilai-nilai solidaritas sosial pada pelajar agar senantiasa hidup saling menghargai serta menciptakan ketertarikan dan ketergantungan antara manusia demi terciptanya tujuan bersama. Ketertarikan dan ketergantungan antara manusia satu dengan yang lainnya mendorong manusia untuk membentuk kelompok-kelompok masyarakat yang disebut kelompok sosial atau social group.

Kelompok sosial (social group) adalah himpunan atau kesatuan manusia yang hidup bersama. Hubungan ini menyangkut kaitan timbal balik yang saling mempengaruhi, kesadaran untuk saling menolong, dan kesadaran saling membutuhkan satu sama lain (Esti Ismawati: 38).

Pembentukan kelompok diawali dengan adanya perasaan atau persepsi yang sama dalam memenuhi kebutuhan. Setelah itu akan timbul motivasi untuk memenuhinya, sehingga ditentukanlah tujuan yang sama dan akhirnya interaksi yang terjadi akan membentuk sebuah kelompok.

Pada dasarnya, pembentukan kelompok dapat diawali dengan adanya persepsi, perasaan atau motivasi, dan tujuan yang sama dalam memenuhi kebutuhannya. Kita sebagai makhluk sosial tidak akan bisa hidup tanpa bantuan orang lain. Salah satu bentuk kerja sama kita dengan orang lain yaitu dengan membentuk kelompok sosial. Dalam sebuah kelompok sosial dapat membantu kita untuk mempermudah menyelesaikan suatu urusan, tugas atau tujuan dengan cara bekerja sama.

Kelompok sosial adalah himpunan atau kesatuan manusia yang hidup bersama. Ada aksi dan ada reaksi. Pelakunya lebih dari satu. Antara individu dengan individu, individu dengan kelompok dan antara kelompok dengan kelompok. Contoh guru mengajar merupakan contoh kelompok sosial antara individu dengan kelompok.

Pembentukan kelompok dilakukan dengan menentukan kedudukan masingmasing anggota (siapa yang menjadi ketua atau anggota). Interaksi yang terjadi suatu saat akan memunculkan perbedaan antara individu satu dengan lainnya sehingga timbul perpecahan (konflik). Perpecahan yang terjadi biasanya bersifat sementara karena timbul kesadaran arti pentingnya kelompok tersebut, sehingga anggota kelompok berusaha menyesuaikan kepentingan bersama. Akhirnya setelah muncul penyesuaian, perubahan dalam kelompok mudah terjadi.

Masalah yang sering terjadi antar pelajar yaitu: kurangnya kebersamaan antar pelajar sehingga perilaku yang tidak menghargai orang lain dapat terjadi, kemudian, adanya kelompok-kelompok tertentu yang mengakibatkan kesenjangan antar pelajar. Oleh karena itu, pola solidaritas sosial dan kelompok sosial perlu dibentuk dikalangan pelajar.

\section{METODE PENELITIAN}

Metode yang digunakan dalam penelitian ini adalah metode penelitian kualitatif deskriptif dengan memfokuskan penelitian pada " Pola Pembentukan Solidaritas Sosial dalam Kelompok Sosial Antar Pelajar di Kecamatan Baraka Kabupaten Enrekang" Deskriftif yang dimaksud disini adalah dengan menuturkan dan menggambarkan data yang diperoleh secara apa adanya sesuai 
dengan permasalahan yang diteliti barulah kemudian peneliti menarik kesimpulan. Penelitian ini dilaksanakan di Kecamatan Baraka, subjek penelitian ini adalah pelajar di Kecamatan Baraka. Untuk mengetahui ini peneliti mengambil informasi dari beberapa responden yang diambil sebagai sampel dengan tehnik purposive sampling (pengambilan sempel berdasarkan tujuan).Responden (anggota sampel) yang dimaksud adalah. 10 orang pelajar, dengan kriteria : (a) 5 orang SMAN 5 Enrekang dan 5 orang pelajar SMPN 1 Baraka. Dalam penelitian ini jenis data yang di kumpulkan berupa data primer dan data sekunder. Sebagai data primer dalam penelitian ini berupa kata-kata dan tindakan/perilaku orang-orang yang diamati dari hasil wawancara serta observasi, sedangkan data-data sekunder yang didapatkan berdupa dokumen tertulis, gambar dan foto-foto. Data yang terkumpul dianalisis dengan menggunakan teknik analisis secara kualitatif deskriptif. Data dari hasil observasi dan wawancara dikelompokkan selama atau sesudah analisis data dilakukan telaah keputusan yang relevan dengan masalah dalam penelitian ini. Analisi ini dilakukan dengan cara menyusun, mereduksi data, mendisplay data yang dikumpulkan dari berbagai pihak dan memberikan verifikasi untuk disimpulkan.

\section{PEMBAHASAN}

\section{Pola pembentukan solidaritas sosial dalam kelompok sosial anatara pelajar}

Hamidah (2011:21-22) dalam hukum Romawi dikatakan bahwa solidaritas menunjuk pada idiom " semua untuk masing-masing dan masing untuk semua." Tidak jauh dari hukum romawi, bangsa Perancis mengaplikasikan terminologi solidaritas pada keharmonisan sosial, persatuan nasional dan kelas dalam masyarakat. Solidaritas sosial menunjuk satu keadaan hubungan antara individu dengan kelompok yang ada pada suatu komunitas masyarakat yang didasari pada moral dan kepercayaan yang dianut bersama yang diperkuat oleh pengalaman bersama.

Emil Durkheim bahwa solidaritas adalah keadaan saling percaya antara para anggota dalam suatu kelompok atau komunitas. Kalau orang saling percaya mereka akan menjadi satu/menjadi persahabatan, menjadi saling hormat menghormati, menjadi terdorong untuk bertanggung jawab dan memperhatikan kepentingan bersama. Konsep solidaritas sosial merupakan konsep sentral Emile Durkheim (1858-1917) dalam mengembangkan teori Sosiologi. Durkheim (dalam Lawang, 1994:181) menyatakan bahwa solidaritas sosial merupakan suatu keadaan hubungan antara individu dan atau kelompok yang didasarkan pada perasaan moral dan kepercayaan yang dianut bersama dan diperkuat oleh pengalaman emosional bersama. Solidaritas menekankan pada keadaan hubungan antar individu dan kelompok dan mendasari keterikatan bersama dalam kehidupan dengan didukung nilai-nilai moral dan kepercayaan yang hidup dalam masyarakat. Wujud nyata dari hubungan bersama akan melahirkan pengalaman emosional, sehingga memperkuat hubungan antar mereka.

Menurut Durkheim, berdasarkan hasilnya, solidaritas dapat dibedakan antara solidaritas positif dan solidaritas negatif. Solidaritas negatif tidak menghasilkan integrasi apapun, dan dengan demikian tidak memiliki kekhususan, sedangkan solidaritas positif dapat dibedakan berdasarkan ciri-ciri:

1. Yang satu mengikat individu pada masyarakat secara langsung, tanpa 
perantara. Pada solidaritas positif yang lainnya, individu tergantung dari masyarakat, karena individu tergantung dari bagian-bagian yang membentuk masyarakat tersebut.

2. Solidaritas positif yang kedua adalah suatu sistem fungsi-fungsi yang berbeda dan khusus, yang menyatukan hubungan-hubungan yang tetap, walaupun sebenarnya kedua masyarakat tersebut hanyalah satu saja. Keduanya hanya merupakan dua wajah dari satu kenyataan yang sama, namun perlu dibedakan

3. Dari perbedaan yang kedua itu muncul perbedaan yang ketiga, yang akan memberi ciri dan nama kepada kedua solidaritas itu. Ciri-ciri tipe kolektif tersebut adalah individu merupakan bagian dari masyarakat yang tidak terpisahkan, tetapi berbeda peranan dan fungsinya dalam masyarakat, namun masih tetap dalam satu kesatuan.

Menurut Josep S Roucek dan Roland S Warren kelompok sosial adalah suatu kelompok yang meliputi dua atau lebih manusia, yang diantara mereka terdapat beberapa pola interaksi yang dapat dipahami oleh para anggotanya atau orang lain secara keseluruhan.

\section{a. Proses Terbentuknya Kelompok Sosial}

Menurut Abdul Syani, terbentuknya suatu kelompok sosial karena adanya naluri manusia yang selalu ingin hidup bersama. Manusia membutuhkan komunikasi dalam membentuk kelompok, karena melalui komunikasi orang dapat mengadakan ikatan dan pengaruh psikologis secara timbal balik. Ada dua hasrat pokok manusia sehingga ia terdorong untuk hidup berkelompok, yaitu:
1. Hasrat untuk bersatu dengan manusia lain di sekitarnya

2. Hasrat untuk bersatu dengan situasi alam sekitarnya

\section{b. Syarat Terbentuknya Kelompok Sosial}

Kelompok-kelompok sosial merupakan himpunan atau kesatuan manusia yang hidup bersama dan saling berinteraksi. Untuk itu, setiap himpunan manusia agar dapat dikatakan sebagai kelompok sosial, haruslah memenuhi persyaratan sebagai berikut:

1. Setiap anggota kelompok memiliki kesadaran bahwa dia merupakan bagian dari kelompok yang bersangkutan.

2. Ada kesamaan faktor yang dimiliki anggota-anggota kelompok itu sehingga hubungan antara mereka bartambah erat. Faktor-faktor kesamaan tersebut, antara lain
a. Persamaan nasib
b. Persamaan kepentingan
c. Persamaan tujuan
d. Persamaan ideologi politik
e. Persamaan musuh

\section{Dampak pola pembentukan solidaritas sosil dalam kelompok sosial antar pelajar}

Dampak yang sering ditimbulkan dengan adanya pola pembentukan solidaritas sosial dalam kelompok sosial antara pelajar adalah terciptanya keharmonisan terhidarnya konflik, terjadinya ketenangan bagi masyarakat dan juga terciptanya kerja sama baik secara pertikal maupun secara horisontal. Pola pembentukan solidaritas dianggap berhasil apa bila ketakutan -ketakutan atau keresahan masyarakat dapat teratasi misalnya munjulnya kelompok pelajar yang mengtas namakan geng dan biasanya 
menyalah gunakan geng tersebut misalnya tindakan kriminal, perampokan, pencurian, penipuan, dan hal-hal yang sipatnya menyimpang.

Menurut Durkheim, berdasarkan hasilnya, solidaritas dapat dibedakan antara solidaritas positif dan solidaritas negatif. Solidaritas negatif tidak menghasilkan integrasi apapun, dan dengan demikian tidak memiliki kekhususan, sedangkan solidaritas positif dapat dibedakan berdasarkan ciri-ciri:

(1) Yang satu mengikat individu pada masyarakat secara langsung, tanpa perantara. Pada solidaritas positif yang lainnya, individu tergantung dari masyarakat, karena individu tergantung dari bagian-bagian yang membentuk masyarakat tersebut.

(2) Solidaritas positif yang kedua adalah suatu sistem fungsi-fungsi yang berbeda dan khusus, yang menyatukan hubungan-hubungan yang tetap, walaupun sebenarnya kedua masyarakat tersebut hanyalah satu saja. Keduanya hanya merupakan dua wajah dari satu kenyataan yang sama, namun perlu dibedakan

(3) Dari perbedaan yang kedua itu muncul perbedaan yang ketiga, yang akan memberi ciri dan nama kepada kedua solidaritas itu. Ciri-ciri tipe kolektif tersebut adalah individu merupakan bagian dari masyarakat yang tidak terpisahkan, tetapi berbeda peranan dan fungsinya dalam masyarakat, namun masih tetap dalam satu kesatuan.

Menurut Durkheim dapat dibedakan dua macam solidaritas positif yang dapat ditandai oleh ciri-ciri sebagai berikut:

a) Pada solidaritas pertama, seorang warga masyrakat secara langsung terikat kepada masyrkat. Di dalam hal solidaritas yang kedua seorang warga masyrakat tergantung kepada masyrakat, karena dia tergantung pada bagian-bagian masyrakat yang bersangkutan.

b) Solidaritas kedua adalah masyarakat merupakan tidak dilihat dari aspek yang sama. Dalam hal pertama, masyrakat merupakan kesatuan kolektif dimana terdapat kepercayaan dan perasaan yang sama. Sebaliknya pada hal kedua masyrakat merupakan suatu sistemyang terdiri dari bermacam-macam fungsi yang merupakan hubungan-hubungan yang tetap, sebetulnya keduanya merupakan suatu gabungan, akan tetapi dilihat dari sudut-sudut yang berbeda.

Dari kedua perbedaan tersebut timbullah perbedaan lain yang dapat dipakai untuk menentukan karakteristik dan namadua macam solidaritas di atas.

Solidaritas pertama diatas dapat terjadi dengan kuatnya apabila cita-cita bersama dari masyrakat yang bersangkutan secara kolektif lebih kuat serta lebih intensif dari pada cita-cita masing-masing warganya secara individual. Solidaritas ini oleh Durkheim dinamakan solidritas mechanikal solidarity (solidaritas mekanis) yang mana dapat dijumpai pada masyrakat yang secara relatif sederhana dan homogen. Hal ini disebabakan karena keutuhan masyarakat tersebut dijamin oleh hubungan atara manuasia yang erat, serta adanya tujuan bersama. Solidaritas yang kedua dinmakanoleh Durkheim sebagai organic solidarity (solidaritas organis) yang terdapat pada masyarakat yang lebih moderen danlebih kompleks, yaitu masyrakat yang ditandai oleh pembagian kerja yang kompleks (Soerjono Soekanto: 49-50).

\section{KESIMPULAN}

Pola pembentukan solidaritas sosial dalam kelompok sosial antara pelajar di 
Kecamatan Baraka adalah suatu cara untuk membentuk karakter dan kerukunan anatara pelajar sehingga keharmonisan dan kerja sama akan terjalin baik antar kelas maupun antar sekolah. Dan pada akhirnya akan melahirkan generasigenerasi yang berkarakter yang dapat membawa perubahan yang lebih baik untuk bangsa dan negara.

Dampak pola pembentukan solidaritas sosial dalam kelompok sosial anatara pelajar di Kecamatan Baraka adalah terjadinya hubungan kerja sama, terjadinya keharmonisan, terhindarnya dari berbagai jenis konflik terciptanya keamanan, ketentraman dan tentunya hal yang paling penting adalah terbentuknya karakter pelajar yang mencerminkan sosok pelajar yang akan menjadi generasi emas di masa yang akan datang.

\section{Daftar Pustaka}

[1] Ismawati, Esti, . (2012). Ilmu Sosial Budaya dasar: Jogyakarta: Ombak

[2] Jones, PIP. (2010). Pengntar Teori-Teori Sosial. Jakarta: Yayasan Pustaka Obor Indonesia.

[3] Johnson, Doyle Paul.(1986). Teori Sosiologi Klasik dan Moderen. Universitas of South Florida diindonesiakan oleh: Robert M. Z. Lawang: Gramedia Jakarta.

[4] Kolip, Usman \& Setiadi. Elli M. (2011). Pengantar Sosiologi. Jakarta: Kencana.

[5] Maryati, Kun.\& Sryawati, Juju. (2007). Sosoilogi untuk SMA dan MA Kelas XI. Jakarta: Erlangga Media Group.

[6] Moleong, Lexy J. (2014). Metodologi Penelitian Kualitatif. Bandung: Remaja Rodaskarya.

[7] Narwoko,Dewi \& Suyanto Bagong, (2011). Sosiologi Teks Pengantar dan Terapan. Edisi keempat. Jakarta: Pernada Media Grout.

[8] Narwoko, J.Dwi dan Bagong, Suyanto,. (2004). Sosiologi Teks Pengantar dan Terapan. Surabaya : Kencana.
[9] Nugroho, Riant. (2008). Gender dan Administrasi Publik. Yogyakarta : pustaka Pelajar.

[10] Prastomo, Andi. (2012). Metode Penelitian Kualitatif. Jogyakatra: Ar-ruz Media.

[11] Prambudi, Anas. (2012). Subordinasi Dalam Bias Gender. Skripsi tidak diterbitkan : Skripsi Fakultas Ilmu Pengetahuan Budaya UI.

[12] Rachman, Deni. dkk. (2006). Jurnal Perempuan Untuk Pencerahan dan Kesetaraan. Jakarta : Yayasan Jurnal Perempuan.

[13] Ritzer, George. (2012). Teori Sosiologi (Dari Sosiologi Klasik Sampai Perkembanagan Terakhir Postmodern). Yogyakarta: Pustaka belajar.Sarderson, Stephenk. (2011). Makro Sosiologi. Jakarta : Rajawali Pers.

[14] Sarderson, Stephenk. (2011). Makro Sosiologi. Jakarta : Rajawali Pers.

[15] Soekanto, Soerjono. (2010). Sosiologi Suatu Pengantar. Jakarta: Rajawali Pers

[16] Soekanto, Soerjono. (2011). Pokok-Pokok Sosiologi Hukum. Jakarta: Rajawali pers

[17] Soyomukti, Nurani. (2010). Pengantar Sosiologi. Trenggalek : Ar. Ruzz Media.

[18] Sugihastuti dan Istana Hadi Saptiawan. (2007). Gender dan Inferioritas Perempuan. Yogyakarta : Pustaka Belajar.

[19] Sugiyono. (2013). Metode Penelitian Kuantitatif, Kualitatif, dan R\&D. Bandung : Alfabeta

[20] Sugiyono. (2011). Metodepenelitian Kuatitatif dan $R \& D$. Bandung alfa beta.

[21] Tukijan Eddy,dkk. (2009). Sosiologi Pendidikan, Jakarta: Depatemen Pendidikan Nasional.

[22] Usman, Husnaini dan Purnomo Setiady Akbar. (2009). Metodologi Penelitian Sosial. Jakarta: Bumi Aksara.

\section{Profil Penulis:}

Saidang was born in Loka-Enrekang, Indonesia. He accomplished his master degree in 2006 focusing on the Sosiology at Gajah University, Yogyakarta, Indonesia. He is currently as a lecturer in Non Formal Education at STKIP Muhammadiyah Enrekang, Indonesia. His current interests are on issues related to sociology and non formal education. 